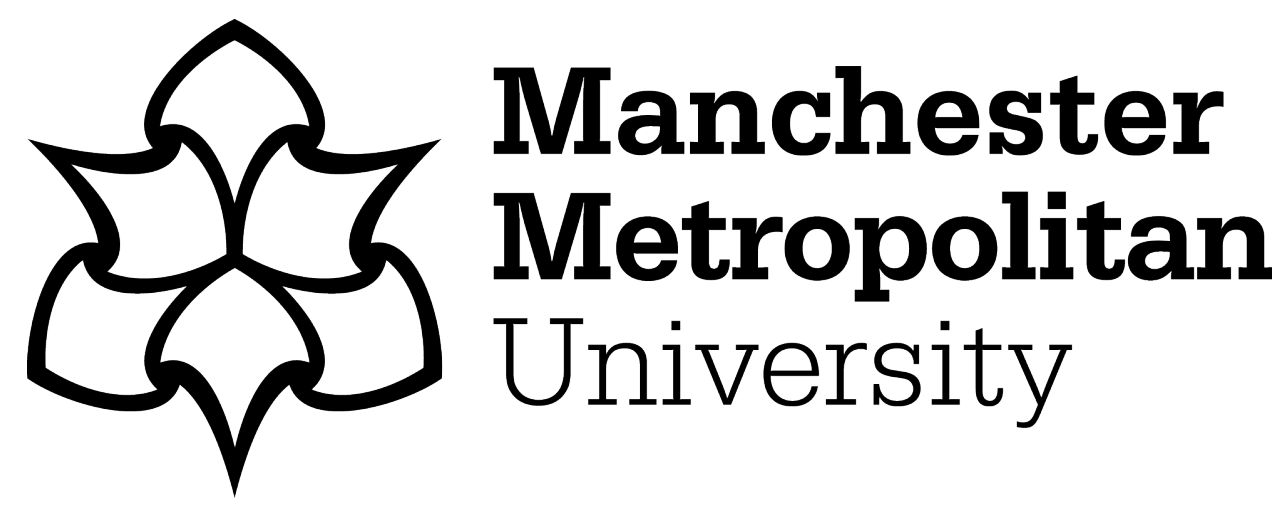

Mei, TX, Li, H, Goodall, RM and Wickens, AH (2002) Dynamics And Control Assessment Of Rail Vehicles Using Permanent Magnet Wheel Motors. Vehicle System Dynamics, 37 (sup1). pp. 326-337. ISSN 0042-3114

Downloaded from: https://e-space.mmu.ac.uk/622231/

Publisher: Taylor \& Francis

DOI: https://doi.org/10.1080/00423114.2002.11666243

Please cite the published version 


\title{
Dynamics And Control Assessment Of Rail Vehicles Using Permanent Magnet Wheel Motors
}

\author{
T. X. MEI' ${ }^{1}$ H. LI' ${ }^{2}$, R. M. GOODALL ${ }^{2}$ and A. H. WICKENS ${ }^{2}$
}

\begin{abstract}
SUMMARY
This paper describes a dynamics and control study for rail vehicles using independentiy-driven wheel motors based upon a novel traction motor where the motor is embedded inside a wheel, and studies the dynamic behaviour of a rail vehicle equipped with such motors. The primary objective of the study is to develop practical control strategies that will use the independently-driven motors, not only to provide adequate traction and dynamic braking control, but also to stabilise the vehicle and to produce the necessary guidance action for the wheels especially on tight curves.
\end{abstract}

\section{INTRODUCTION}

The conventional solid-axle wheelset has been used for railway vehicles for many years. A key advantage of the configuration is that the wheelset has the ability of natural curving and centring, but this is severely compromised by the need for external stabilisation to overcome its inherent instability problem. A typical stabilisation is achieved by applying yaw stiffness to the wheelset, which is known to degrade the curving performance resulting in increased creep force at the wheel-rail contact and inevitable flange contact on tight curves. A number of studies have illustrated that it is possible to solve the design conflict between the stability and curving performance via active control. Some of this research has also shown that a wheelset with independently-rotating wheels will provide a better solution in terms of vehicle performance, ease of control and actuation requirement [1].

The independently-rotating wheelset reduces significantly (almost eliminates) the longitudinal creepage associated with curving, because the two wheels on the axle are allowed to rotate freely from each other. On the other hand the release of the rotational constraint between the two wheels results in the loss of the natural curving and centring ability. The centring effect can be slightly restored by gravitational force if a 'worn' type of wheel profile is used, but this is not large enough to provide self-curving behaviour [2]. It is therefore recognised that some form of steering control for guidance is necessary. In addition, instability is still observed from the independently-rotating wheelset $[2,3]$ and an additional effect is required to avoid

\footnotetext{
'School of Electronic \& Electrical Engineering, Leeds, LE2 9JT, UK

${ }^{2}$ Loughborough University, LEII 3TU, UK
} 
potential oscillations in practice. There are a number of options possible to overcome the problems. Passive solutions proposed include the partial coupling between the two wheels and the use of magnetic steering [4]. Full active control may be used to provide both the guidance action and stabilisation for the wheelset by applying a control torque in the yaw direction [1]. Alternatively a control torque may be applied in the rotational direction via a superimposed gearbox or separate motors [5].

The basis of the project for which the study described in this paper has been carried out is to reduce the large costs that have become endemic in light rail vehicles and systems. The high costs are associated with the high weight of many socalled "light rail" vehicles. The introduction of low floor technology has increased costs even more, and has often given rise to high mechanical complexity. The development described in this paper has as its basis the replacement of many mechanical components with software-based computation acting on steerable wheel motors. The resulting vehicle will be mechanically simple and of low weight; consequently it will offer a large reduction in maintenance costs of both vehicle and infrastructure, and give very low energy consumption. This will further enhance the environmental benefits of light rail systems, and make them more affordable.

This study is based upon a vision of future rail vehicles in which the suspension, guidance, traction and braking functions are all provided through integrated control of independently-driven wheels, leading to vehicles that are light, energy efficient and mechanically simple. It starts from a practical arrangement: an innovative concept of wheel motor that has been developed (and patented) to provide traction and braking directly without the need for gearboxes or other transmission components $[6,7]$. This paper analyses the dynamic characteristics of the scheme in order to provide the basis for developing an integrated solution for a rail vehicle driven by those wheel-motors.

\section{DESCRIPTION OF MOTOR AND VEHICLE CONCEPT}

The concept of the wheel-motor is to incorporate a permanent magnet synchronous motor as an integral part of a rail wheel, removing all mechanical power transmission components. Figure 1 shows a prototype of the permanent magnet synchronous wheel motor, and Figure 2 provides some more detail of the mechanical scheme. the wheel rim, motor rotor and magnetic circuit are combined to reduce weight and size. The field system is based on high energy permanent magnets, that can operate at high flux density and high coercive force, and have small mass and volume. These magnets form the motor poles, and are attached to the wheel rim, which in turn carries the steel tyre with interposing rubber blocks to form a resilient wheel assembly. The rotor revolves round an internal stator consisting of an annular ring of slotted laminations carrying three phase windings. The stator is supported on a 'spider' that incorporates water-cooling. The whole unit forms a compact drive, little larger than a conventional wheel, and of total mass about $350 \mathrm{~kg}$ with tyre. The motor has a high efficiency, about $97 \%$ over most of the load-speed range, from electrical input to mechanical power at the rail. Each wheel revolves round a fixed stub axle, via two taper roller bearings, these being the only wearing parts. The output of the motor is $60 \mathrm{~kW}$ continuous, and gives a peak tractive effort of $5670 \mathrm{~N}$. 
This is based on a 10 tonne vehicle carrying 100 passengers accelerating at $1.3 \mathrm{~m} / \mathrm{s}^{-2}$, using four wheel-motors.

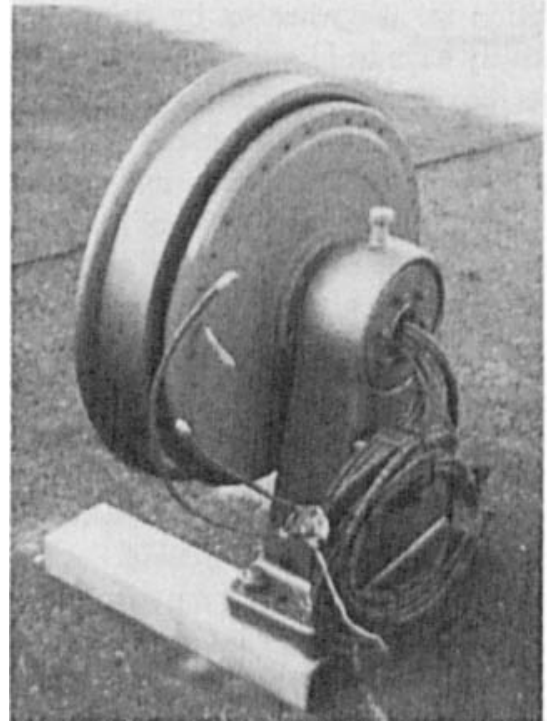

Fig. 1. Photograph of wheel motor

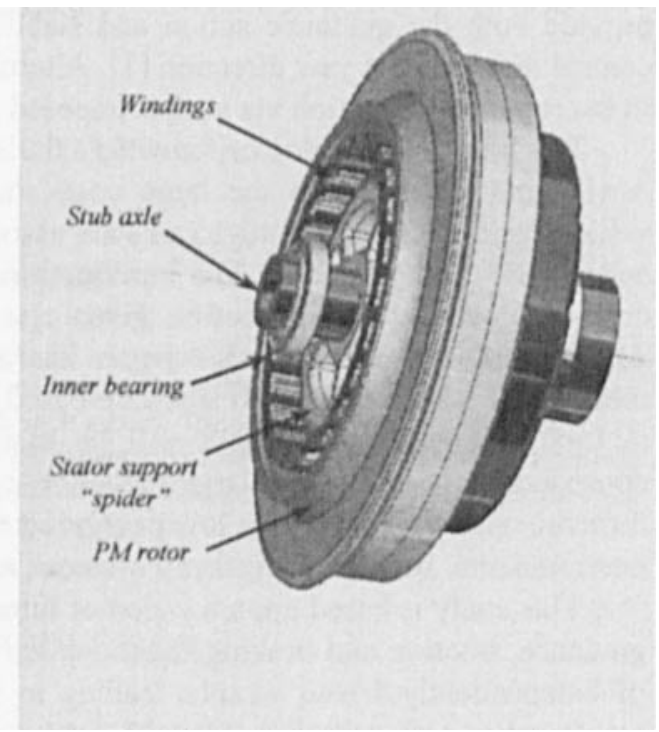

Fig. 2. Wheel motor details

As the wheels are inherently independently-driven, it is possible to provide steering by controlling the adjacent wheels to rotate at different speeds, and with suitable control the vehicle can negotiate curves without slipping. The wheels can either be mounted on a common axle, or on individual stub-axles so they can pivot around a vertical axis away from the wheel centre. Either way they can be steered around curves by varying their relative speeds. With the wheels running at the correct speed for the curve radius, the steering force will fall to zero when the wheels are properly aligned. With a common axle the steering effect due to traction/braking forces is cancelled out, but with the stub-axle arrangement a cross member needs to be provided between adjacent wheels such that only differential traction forces will give wheel steering.

A plan-view vehicle scheme with four wheels (hence four independent wheel motors) is used in the study. The vehicle parameters are given in the Appendix these are chosen to meet the requirement of typical tram vehicles. There are no bogies used for the vehicle - the wheels are mounted onto light frames that are connected to the vehicle body via soft secondary suspensions. The pivotted wheel arrangement with a cross connection is mechanically novel and has not yet been detailed. However it can be shown to have the same fundamental dynamic characteristics as an independently-rotating wheelset having a common axle, albeit with much reduced yaw inertia, and accordingly the vehicle model uses this arrangement. 


\section{FUNDAMENTAL ANALYSIS}

It is important to recognise that, although the mechanical connection between the wheels has disappeared, they nevertheless are connected via the motors and the inverters, and the dynamic characteristics of this connection depend upon the electronic control. The basic strategy mentioned before, in which steering is achieved by varying the relative speed between the wheels on curves, essentially provides an axle (albeit one which is capable of a speed differential for steering).

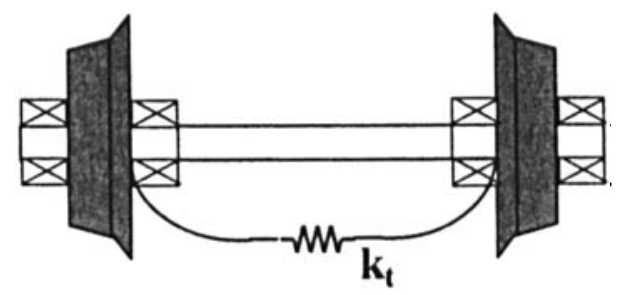

Fig. 3. Single wheel-pair configuration

In order to understand the dynamics better, a simple single wheelset model has been studied. The basic straight track stability of such an arrangement was analysed, where a simple rotational stiffness $k_{t}$ between the two wheels is initially used to represent the characteristic of a synchronous motor in which the torque is proportional to the load angle. The wheels could be cylindrical because coning or profiling is not necessary for steering. However there is a tendency for wheels to wear to the shape of the rail even without curve wear, and higher conicity values need to be considered. Accordingly a value of 0.15 was taken as a starting point, although substantial variations around this value must be considered. The analysis showed that, even though the wheels are mechanically independent, the electrical/electronic connection results in a different form of instability. The classic kinematic oscillation of a solid-axle wheelset therefore still occurs, and in addition

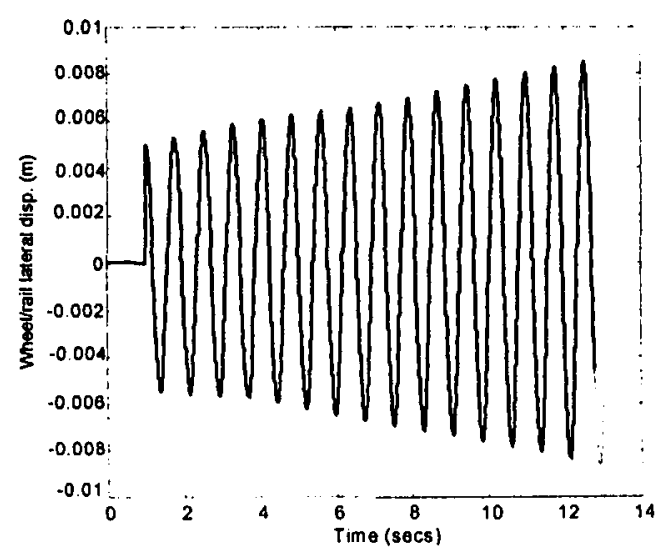

Fig. 4. Lateral wheel-rail displacement for $5 \mathrm{~mm}$ step input 
there is a torsional oscillatory mode (at around $5 \mathrm{~Hz}$ ) because the "electro-magnetic axle" is not nearly as stiff as the mechanical axle. Figure 4 shows a simulated time response of the essential arrangement for a lateral step of $5 \mathrm{~mm}$ in the track at a speed of $10 \mathrm{~ms}^{-1}$, from which the unstable kinematic mode is evident.

The low damping in the torsional mode can barely be seen in the lateral displacement results, but Figure 5 shows the individual wheel velocities which makes this very clear. Although the relative speeds are quite small, nevertheless this kind of dynamic characteristic will not be acceptable in practice and needs to be dealt with.

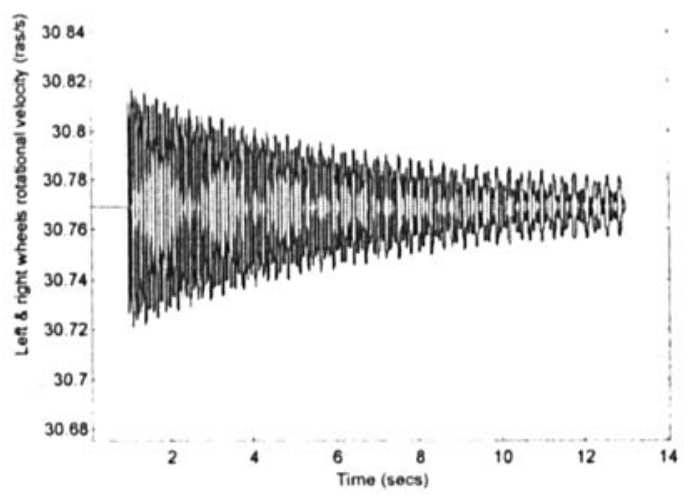

Fig. 5. Wheel velocities for $5 \mathrm{~mm}$ step input (unconstrained)

A small amount of torsional damping can be added by active means (in a manner to be determined), and, when combined with the usual approach of using yaw stiffness to stabilise the kinematic mode, a much more satisfactory response is obtained. Figure 6 gives the $5 \mathrm{~mm}$ step response with a yaw stiffness of $1.3 \mathrm{MNm}^{-1}$ and a torsional damping of $460 \mathrm{Nms} / \mathrm{rad}$ - this indicates a stable kinematic response and very little evidence of torsional vibration, altogether a more satisfactory performance.

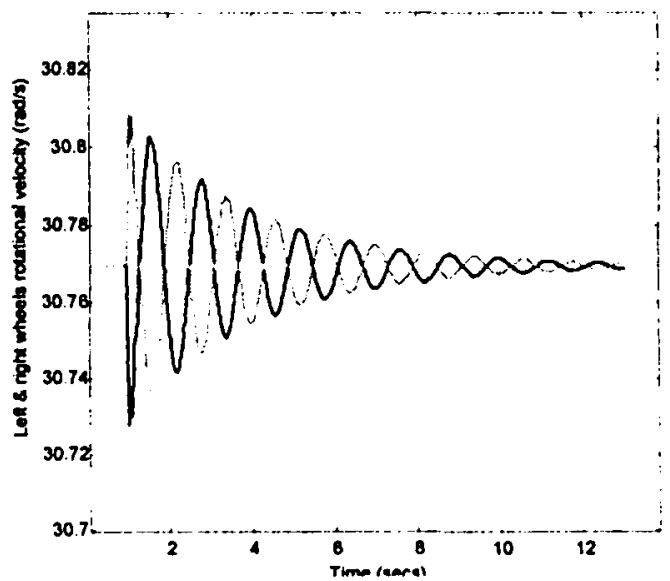

Fig. 6. Wheel velocities for $5 \mathrm{~mm}$ step input (with yaw stiffness and torsional damping) 
This wheelset analysis mainly illustrates what control features are required to provide stability for the basic concept - the next section considers ways in which this can be achieved in the context of a complete vehicle.

\section{VEHICLE DYNAMICS AND CONTROL ASSESSMENT}

In a conventional rail vehicle of any kind the mechanical configuration means that the essential functions of traction, braking, running stability and steering can be considered separately, whereas the mechanical simplicity of this new vehicle concept means that these functions are implicitly integrated. There are four power electronic inverters driving the wheel motors, and all the above-mentioned functionality must be provided via the four control inputs to the inverters - see Figure 7. This section explains the issues involved and gives an indication of how the integrated control can be achieved.

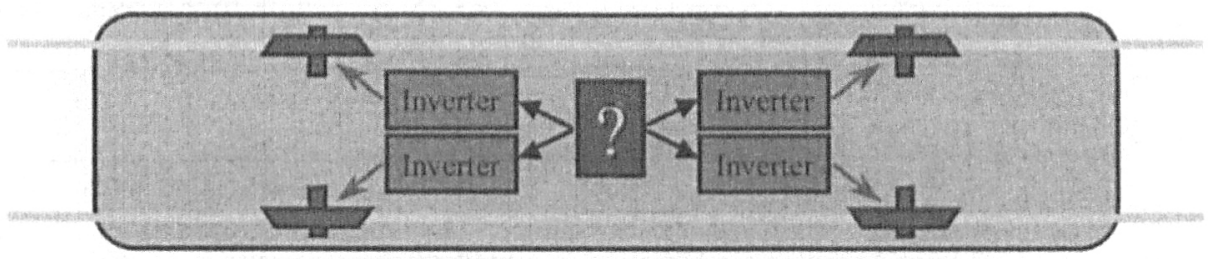

Fig. 7. Basic vehicle scheme

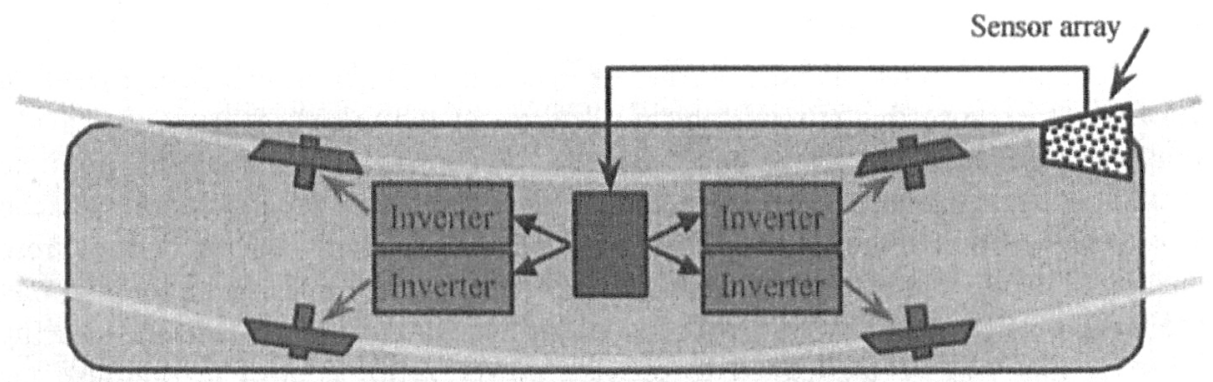

Fig. 8. Steering control scheme

The steering approach developed by the manufacturer of the wheel motor involves sensing the position of the track relative to the front of the vehicle - see Figure 8 . This is done electromagnetically, in effect having an array of inductive metal detectors near the front. The output of this is used to calculate the divergence of the track from straight and the corresponding frequencies required for each wheelmotor to negotiate the track at any point. The wheels thus steer into the curves, and this action offers much reduced rates of wear, the possibility of a long wheelbase, and the elimination of bogies. This then is the basic steering control principle, although as explained in Section 3 other stabilising features are necessary in practice. 
Table 1 gives eigenvalues of the vehicle with a fixed frequency applied to all the wheels at a speed of $10 \mathrm{~m} / \mathrm{s}$, i.e. an extension to the fundamental analysis described previously. In addition to the unstable kinematic modes, the very lightly damped modes associated with the torsional motions of the two wheels due to the electrically introduced interactions can again be seen.

Table 1: Eigenvalues of the vehicle with independently-driven wheels $(\mathrm{V}=10 \mathrm{~m} / \mathrm{s})$

\begin{tabular}{ccccl}
\hline Mode & Eigenvalue & $\begin{array}{c}\text { Damping } \\
(\%)\end{array}$ & $\begin{array}{c}\text { Frequency } \\
(\mathrm{Hz})\end{array}$ & \multicolumn{1}{c}{ Notes } \\
\hline $1 / 2$ & $0.0168 \pm 8.14 \mathrm{i}$ & -0.206 & 1.296 & Wheel \\
$3 / 4$ & $0.0123 \pm 8.15 \mathrm{i}$ & -0.151 & 1.297 & kinematic modes \\
\hline $5 / 6$ & $-0.205 \pm 31.8 \mathrm{i}$ & 0.646 & 5.061 & Wheel \\
$7 / 8$ & $-0.205 \pm 31.8 \mathrm{i}$ & 0.646 & 5.061 & torsional modes \\
\hline 9 & $-1.82 \mathrm{e}+3$ & 100 & 289.66 & High frequency \\
10 & $-1.82 \mathrm{e}+3$ & 100 & 289.66 & modes associated \\
11 & $-4.67 \mathrm{e}+3$ & 100 & 743.25 & with four wheels \\
12 & $-4.67 \mathrm{e}+3$ & 100 & 743.25 & \\
\hline $13 / 14$ & $-0.932 \pm 4.82 \mathrm{i}$ & 19.0 & 0.782 & Body \\
$15 / 16$ & $-1.25 \mathrm{e} \pm 5.54 \mathrm{i}$ & 22.0 & 0.904 & modes \\
\hline 17 & 0 & & 0 & Associated with \\
18 & 0 & & 0 & longitudinal \\
19 & $-2.85 \mathrm{e}+3$ & 100 & 453.59 & motions \\
20 & $-2.85 \mathrm{e}+3$ & 100 & 453.59 & of the wheels \\
\hline
\end{tabular}

The basic analysis has been further extended to include the effect of a steering sensor, but because this is mounted on the body of the vehicle it does not have a beneficial effect upon the system stability. Accordingly a variety of possible stabilising strategies have been considered. Figure 9 shows a general control scheme to provide traction/braking control via a vehicle speed input, steering control from the sensor array, and also active stabilisation. Although the manufacturers plan that the motors will essentially be frequency-controlled in accordance with the steering strategy, this will be modulated to provide power factor control to optimise the overall drive efficiency. Since the full detail has not yet been worked out, a modern vector control strategy has been used for the simulation study. This provides highperformance torque control of the motors and thereby effectively provides proper independently-rotating action for the two wheel motors. However this is not then consistent with the steering strategy based upon differential frequency/speed commands on curves, and a loop to control the speed of each wheel motor is included. This provides a means to achieve a desirable curving performance by controlling the wheels to rotate at differential speeds on curves. These loops have a simple PI controller which can be tuned to give accurate speed control, and this also has the effect of overcoming the torsional oscillatory mode because the stiffness between adjacent wheels is substantially increased and damped by the control action. However the wheel speeds are now tightly connected via the electronic control, and 
so this dynamically it is as though there is a solid axle and the corresponding kinematic modes must again be stabilised.

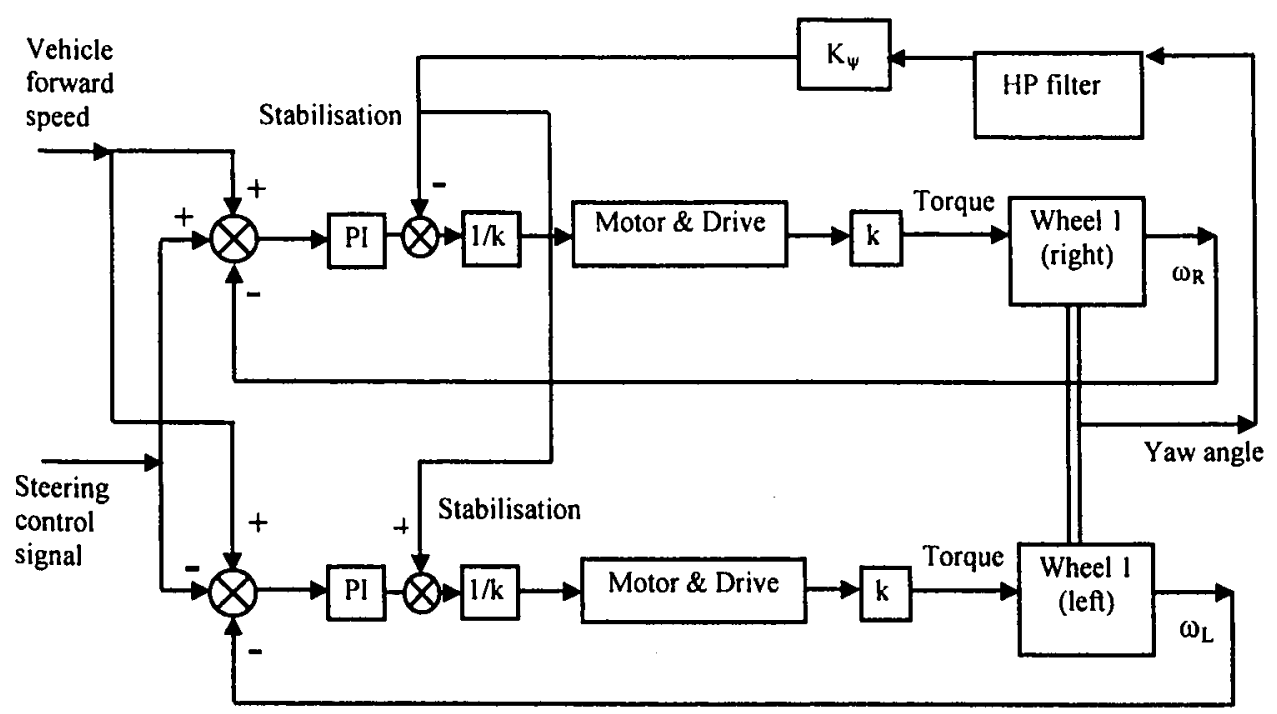

Fig. 9. Overall control scheme

Various stabilisation methods have been studied, and the diagram shows a simple but effective solution in which yaw stiffness is applied actively, but via a high-pass filter so that it only acts at kinematic frequencies and hence does not interfere with the curving action. Figures 10 and 11 show the dynamic responses for wheel-rail displacement and the wheels' rotational speeds at a vehicle speed of $20 \mathrm{~ms}^{-1}$ with a $5 \mathrm{~mm}$ step input on the track. From these graphs it is clear that highlystable and effective straight track performance is achieved.

It is also interesting to see the performance on a curve, in this case a "high speed" curve of $400 \mathrm{~m}$ radius with $1 \mathrm{sec}$ transitions at the top speed of around $20 \mathrm{~ms}^{-1}$. The wheel-rail displacement and wheel velocities for this track feature are seen in Figures 12 and 13. the simulation excludes steering control, and so the lateral displacement on the curve corresponds to natural curving of a solid-axle wheelset these results confirm the statements made earlier that frequency and or velocity control applied to the motors essentially create an "electronic axle", although of course the transient variations in relative wheel speed (clearly seen in Figure 12) are superimposed to provide stability.

The overall control structure is therefore non-trivial, and this generic scheme shows how the partitioning of the traction, braking, steering and stability functions, which on a conventional vehicle is evident in the mechanical arrangement, now appears within the control structure. 


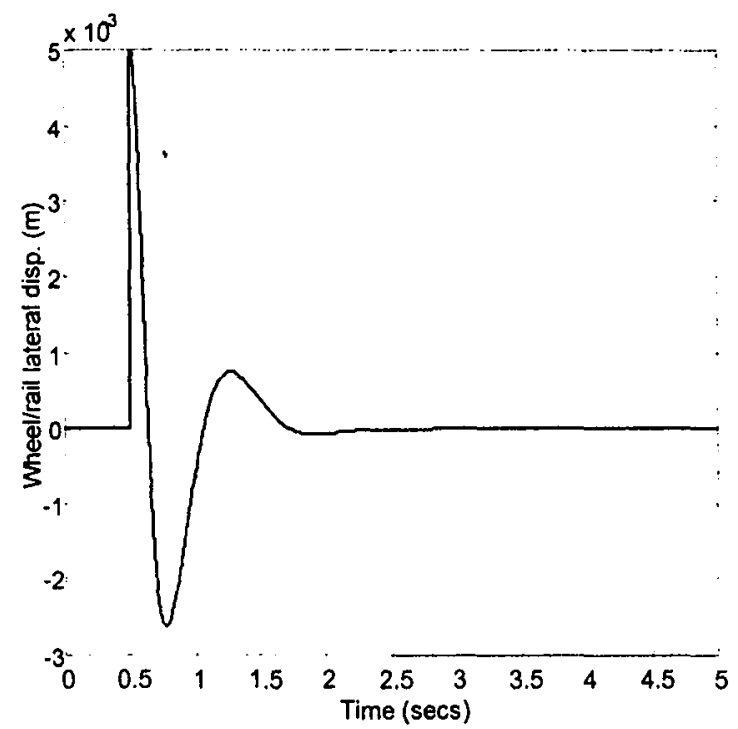

Fig. 10. Leading wheel-rail displacement for $5 \mathrm{~mm}$ step input

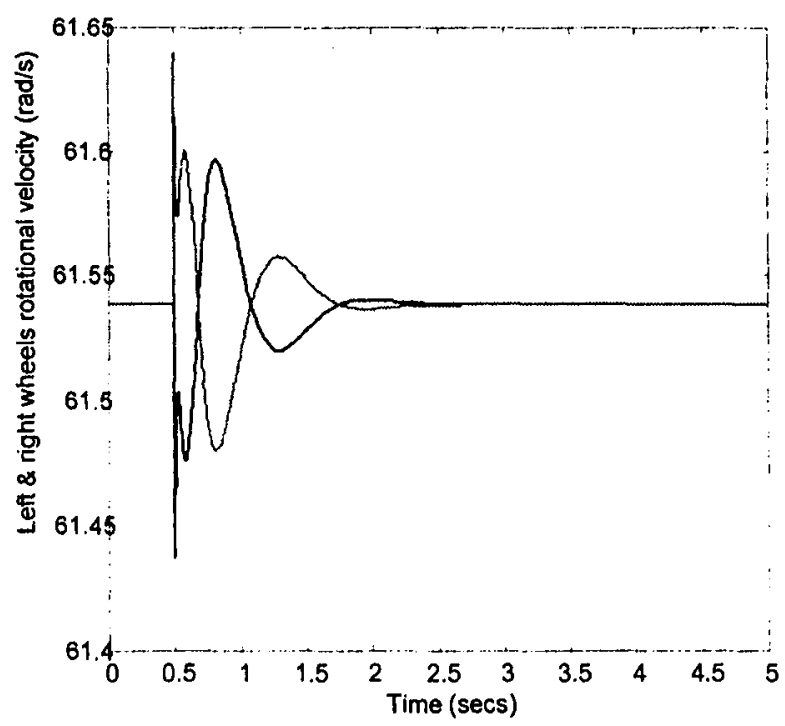

Fig. 11. Leading wheel velocities for $5 \mathrm{~mm}$ step input 


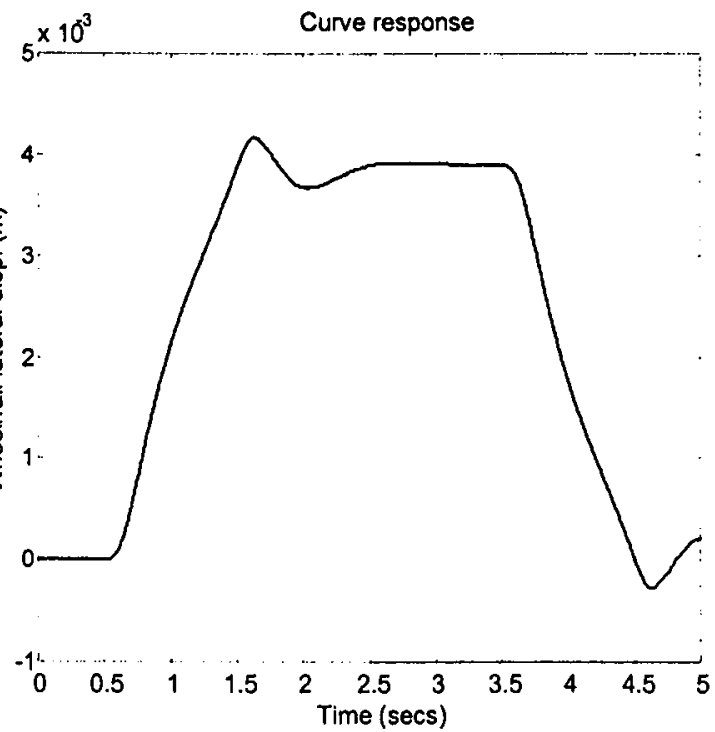

Fig. 12. Leading wheel-rail displacement for vehicle on a $400 \mathrm{~m}$ radius curve

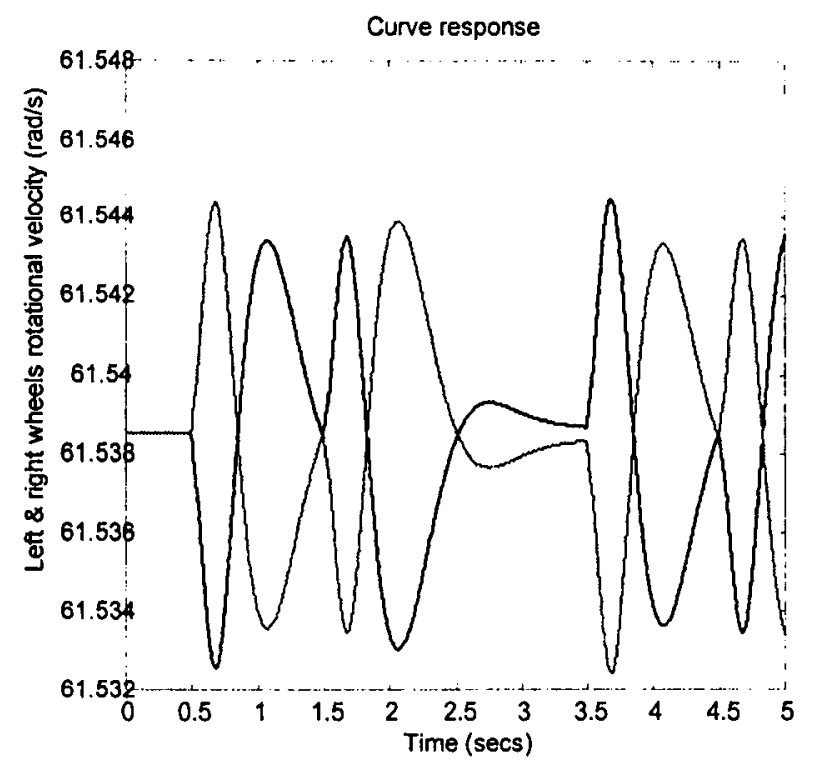

Fig. 13. Leading wheel velocities for vehicle on a $400 \mathrm{~m}$ radius curve

\section{CONCLUSIONS}

The paper has reported on the first stage of a study related to an innovative development for tram and light rail vehicles. The fundamental characteristics of a 
single wheel-pair using independently-driven wheels have been exposed and extended to a vehicle with four such wheels. A control strategy which provides for integrated control of the drive, suspension and drive functions has also been explained, and results given to show that superior performance on straight and curved track can be achieved.

The next stage is to combine the stabilising strategies described in this paper with steering control so that effective curving around the tightest curves $(15 \mathrm{~m})$ can be achieved, and also of course to investigate any interactions which may occur in practice when traction and braking is incorporated. The company with whom the authors are collaborating is currently assembling a full-size demonstrator vehicle, and this will provide the opportunity for experimental verification.

\section{ACKNOWLEDGMENT}

Authors wish to acknowledge both the support of the EPSRC (UK), reference GR/N01019, and the collaboration with SET Ltd (Derby, UK), the developers of the wheel motors.

\section{REFERENCES}

1. Mei, T.X., Nagy, Z., Goodall, R.M. and Wickens, A.H. "Mechatronic solutions for high-speed railway vehicles", Ist IFAC Conference on Mechatronic Systems, 18-20 September 2000, Darmstadt, Germany, pp. $271-276$.

2. Eickhoff, B.M. "The application of independently rotating wheels to railway vehicles", IMechE Proc., Part F, Vol 205, 1991, pp.43-54.

3. Goodall, R.M. and $\mathrm{Li}, \mathrm{H}$. "Solid axle and independently-rotating railway wheelsets - a control engineering assessment ", Journal of Vehicle System Dynamics, Vol. 33, 2000, pp.57-67.

4. Dukkipati, R.V.; Narayana Swamy, S. and Osman, M.O.M., "Independently rotating wheel systems for railway vehicles - a state of the art review", Journal of Vehicle System Dynamics, Vol. 21, 1992, pp.297-330.

5. Gretzschel $M$ and Bose L: A new concept for integrated guidance and drive of railway running gears, Proc Ist IFAC Conference on Mechatronic Systems, Vol. 1, pp 265-270, Darmstadt, Germany, September, 2000.

6. Gibson D: "A new British Tram", Tramways and Urban Transit, Feb 2001, pp.48-49.

7. Goodall $R M$ and Gibson D. "Integrated traction and steering control concepts for trams and light rail vehicles", Proc IMechE Seminar Innovations for new business, 24 May 2001.

\section{APPENDIX: SYMBOLS AND PARAMETERS}

$\mathrm{r}_{0}=0.325 \mathrm{~m}$

$\lambda=0.15$

$\mathrm{a}=3.75 \mathrm{~m}$

$\mathrm{I}=0.7175 \mathrm{~m}$

$\mathrm{I}_{\mathrm{w}}=566 \mathrm{kgm}^{2}$

$\mathrm{I}_{\mathrm{r}}=37 \mathrm{kgm}^{2}$

$\mathrm{I}_{\mathrm{b}}=112500 \mathrm{kgm}^{2}$

$\mathrm{m}_{\mathrm{w}}=1100 \mathrm{~kg}$
Wheelset radius

Conicity

Semi wheel-wheel spacing

Half gauge

Wheelset yaw inertia

Wheel rotation inertia

Vehicle body yaw inertia ( $15 \mathrm{~m}$ body length)

Wheelset mass 


$$
\begin{aligned}
& \mathrm{m}_{\mathrm{b}}=6000 \mathrm{~kg} \\
& \mathrm{R}=15 \mathrm{~m} \\
& \theta=0 \mathrm{rad} \\
& \mathrm{k}_{\mathrm{y}}=96000 \mathrm{~N} / \mathrm{m} \\
& \mathrm{c}_{\mathrm{y}}=7500 \mathrm{Ns} / \mathrm{m} \\
& \mathrm{k}_{\mathrm{r}}=108.9 \mathrm{kNm} / \mathrm{rad} \\
& \mathrm{k}_{\mathrm{t}}=50000 \mathrm{Nm} / \mathrm{rad}
\end{aligned}
$$

Vehicle body/frame mass

Minimum curve radius

Cant angle on minimum radius curve

Lateral suspension stiffness per wheelset

Lateral suspension damper per wheelset

Yaw stiffness per wheelset

Torsional stiffness per wheelset (due to motors) 